\title{
Hydrophobic and antibacterial textile fibres prepared by covalently attaching betulin to cellulose
}

\author{
Tianxiao Huang $\mathbb{D} \cdot$ Chao Chen $\cdot$ Dongfang Li $\cdot$ Monica Ek
}

Received: 6 September 2018/ Accepted: 14 January 2019/Published online: 21 January 2019

(C) The Author(s) 2019

\begin{abstract}
Betulin, a natural compound extractable from the outer bark of birch, can be used to improve the properties of cellulosic textile fibres. Herein, oxidation was performed to prepare carboxyl-functionalized cellulose, which was subsequently covalently attached by betulin through esterification. The surface-modified cellulosic textile fibres showed a substantially improved hydrophobicity, as indicated by a water contact angle of $136^{\circ}$. Moreover, the material showed excellent antibacterial properties, as indicated by over $99 \%$ bacterial removal and growth inhibition, in both Gram-positive and Gram-negative bacterial assays. The method of surface-modification of the cellulosic materials adapted in this study is simple and, to the best of our knowledge, has not been carried out before. The results of this study prove that betulin, a side-stream product produced by forest industry, could be used in value-added applications, such as for preparing functional materials. Additionally, this modification route can be envisaged to be applied to other cellulose sources (e.g., microfibrillated cellulose) to achieve the goal of functionalization.
\end{abstract}

T. Huang · C. Chen · D. Li · M. Ek $(\bowtie)$

Department of Fiber and Polymer Technology, School of

Engineering Sciences in Chemistry, Biotechnology and

Health, KTH Royal Institute of Technology,

10044 Stockholm, Sweden

e-mail: monicaek@kth.se
Keywords Antibacterial property - Betulin ·

Cellulose $\cdot$ Hydrophobicity $\cdot$ Surface modification

\section{Introduction}

Betulin (Scheme 1) is one of the main components of the extract from the outer bark of the birch tree. Up to $30 \%$ of the dry weight of birch bark extract is betulin, which gives the tree bark its white colour (Krasutsky 2006). Betulin can readily be obtained by solvent extraction with various organic solvents, such as ethanol and heptane (Cao et al. 2007). In addition to the conventional methods of obtaining betulin, it has also been reported that betulin could be extracted by supercritical carbon dioxide $\left(\mathrm{SC}-\mathrm{CO}_{2}\right)$ (Yu-hong et al. 2003), classical reflux boiling and pressurized liquid extraction (Fridén et al. 2016). Recently, more sustainable approaches that utilize green solvents such as pine monoterpenes and limonene to extract purer betulin have been reported (Grazhdannikov et al. 2018).

Due to its high crystallinity, betulin can cause deposition problems in the papermaking process, as the kraft digestion process cannot fully dissolve betulin (Sharoyan 2011). Therefore, to minimize problems, the removal of betulin by efficient debarking is necessary. The debarking process generates a tremendous amount of birch bark, containing 


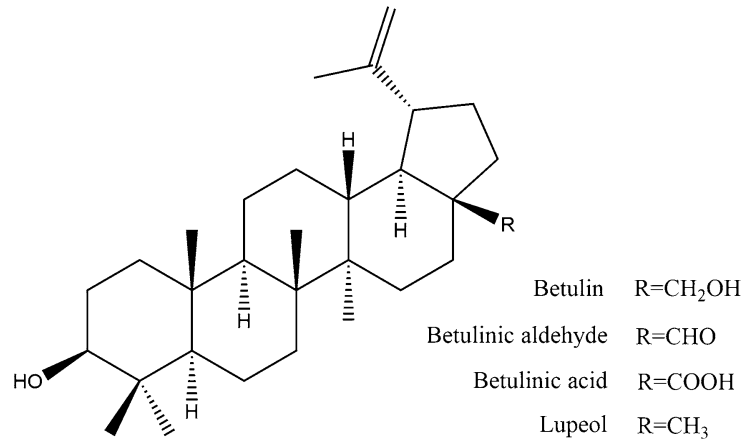

Scheme 1 Structure of major chemicals from birch bark extractive

abundant betulin. However, currently, the peeled bark is typically incinerated to provide thermal energy $(\mathrm{Lu}$ et al. 2006). According to the biomass value pyramid established elsewhere (Berbel and Posadillo 2018), using natural resources as solid fuels is ranked as the lowest valuable action, while production of chemicals or materials based on biomass can increase the value. This has motivated us to explore the possibility of using betulin in value-added applications, rather than only for energy production. Betulin has anti-inflammatory, anticancer and antimicrobial properties, and thus it has been used in the production of pharmaceuticals and medicines (Fălămaş et al. 2011; Fridén et al. 2016; Yu-hong et al. 2003). In our previous study, it was reported that betulin and its derivatives could be physically adhered onto cellulosic textile fibres to improve their hydrophobicity and water repellency (Huang et al. 2018). Considering these two aspects, we believe it is possible to fabricate a betulin-attached cellulosic textile with improved hydrophobicity as well as antibacterial property. However, the former product from our previous study is a kind of textile with physically adhered betulin particles. The betulin particles on that textile can be liberated when the textile is placed in an aqueous environment, such as by immersion, or by exposure to solvent extraction (Huang et al. 2018). Therefore, that textile cannot be used in antibacterial assays, which needs the textile sample to be immersed in solutions. Based on this, we hypothesize that by creating covalent bonds, which act as a binder, to attach betulin onto cellulosic textile may hinder betulin from being liberated in case of sample washing or solution-based assays.

In this study, cellulosic textiles were first oxidized by 2,2,6,6-tetramethylpiperidine-1-oxy radical
(TEMPO)-mediated oxidation to selectively convert the primary alcohol groups located on the surface of cellulose fibrils or fibril aggregates to carboxyl groups, as described elsewhere (Marković et al. 2017; Saito et al. 2009). Betulin was then covalently attached onto the carboxyl-functionalized cellulose through tartaric acid-catalysed esterification (Hafrén and Córdova 2005; Hafrén et al. 2006; Zhao et al. 2010).

Oxidation and esterification were verified by Fourier transform infrared (FTIR) analysis. The mechanical properties of the prepared materials were tested by a tensile test. Scanning electron microscopy (SEM) was used to obtain surface morphology images. The hydrophobicity and antibacterial properties were the main characteristic properties of the prepared materials and were determined by static water contact angle measurements and antibacterial assays, respectively.

\section{Experimental}

\section{Materials}

Betulin was Soxhlet extracted from the outer bark of birch (Betula verrucosa) with n-heptane as solvent for $48 \mathrm{~h}$ and was obtained as a white powder. The purity of the betulin was $80 \%$, as determined by quantitative ${ }^{1} \mathrm{H}$ NMR with TMS as internal standard. Commercial cellulosic textiles $(100 \%$ cotton, Hemtex, Stockholm, Sweden) were used as the source of cellulose. The solvents and chemicals were used as received without further purification: tetrahydrofuran (THF, 99.99\%), $1 \mathrm{M}$ hydrochloric acid $(\mathrm{HCl})$, toluene $(\geq 99.5 \%)$, phenolphthalein, sodium hypochlorite solution (NaClO, 10\%), 2,2,6,6-tetramethyl-1-piperidinyloxy (TEMPO, 98\%), sodium chlorite $\left(\mathrm{NaClO}_{2}, 80 \%\right)$, acetic acid $\left(\mathrm{CH}_{3} \mathrm{COOH}, \geq 99.7 \%\right)$, sodium acetate anhydrous $\left(\mathrm{CH}_{3} \mathrm{COONa}, \geq 99 \%\right)$, sodium borohydride $\left(\mathrm{NaBH}_{4}, \geq 98 \%\right)$, glutaraldehyde (50 wt\%) (Sigma-Aldrich); sodium hydroxide $(\mathrm{NaOH})$ (VWR International); L(+)-tartaric acid (Scharlau Chemicals).

Pretreatment of cellulosic textiles

The cellulosic textile (approximately $10 \mathrm{mg} \mathrm{cm}^{-2}$ ) was washed by an Electrolux EWC1350 laundering machine at $40{ }^{\circ} \mathrm{C}$ for $2 \mathrm{~h}$ with added non-bleaching washing powder to remove contaminants. 
Subsequently, the cellulosic textile was washed with $2 \mathrm{~g} \mathrm{~L}^{-1}$ of $\mathrm{NaOH}$ solution at $98{ }^{\circ} \mathrm{C}$ for $90 \mathrm{~min}$, followed by washing with distilled water. Afterwards, the cellulosic textile was dried at $105^{\circ} \mathrm{C}$ overnight (Wang et al. 2006). Finally, three $(18 \mathrm{~cm} \times 18 \mathrm{~cm})$ pieces of cellulosic textile samples were cut out, and designated as Ref. cotton.

TEMPO-mediated oxidation and $\mathrm{NaBH}_{4}$ reduction

The TEMPO-mediated oxidation of cellulose was performed as described elsewhere (Marković et al. 2017; Saito et al. 2009) with minor changes. A 3 g sample of Ref. cotton was added to $150 \mathrm{~mL}$ of $0.05 \mathrm{M}$ acetate buffer ( $\mathrm{pH} 4.5)$ and $60 \mathrm{~g}$ of TEMPO $(0.38 \mathrm{~mol})$ and $150 \mathrm{~g}$ of sodium chlorite $(1.66 \mathrm{~mol})$ were dissolved in the mixture. A total of $9.3 \mathrm{~mL}$ of $10 \%$ sodium hypochlorite solution $(15 \mathrm{mmol})$ was added to the mixture, and the mixture was stirred at $500 \mathrm{rpm}$ and $60{ }^{\circ} \mathrm{C}$ for a predetermined time of 15,45 or $180 \mathrm{~min}$ to obtain three oxidized cellulosic textile samples. Next, the mixture was cooled to room temperature, followed by thoroughly washing with deionized water by filtration. A $2.5 \% \mathrm{NaBH}_{4}$ solution (pH adjusted to approximately 9 with $0.5 \% \mathrm{Na}_{2} \mathrm{CO}_{3}$ ) was used to treat the washed textile samples for $2 \mathrm{~h}$ to reduce any trace ketone groups that had formed at the $\beta$-D-glucopyranose C2/C3 position to alcohol groups (Mishra et al. 2012; Tanaka et al. 2016). After the reaction, the reduced textile samples were thoroughly washed with deionized water by filtration. The sodium carboxylate groups in the reduced textile samples were protonated by immersing the textile sample in an $\mathrm{HCl}$ solution ( $\mathrm{pH}$ 2) for $1 \mathrm{~h}$ and then thoroughly washing with deionized water by filtration. Finally, the oxidized cellulosic textiles, containing free carboxyl groups, were air-dried overnight and stored for further use. These samples were denoted as $15 \mathrm{COOH}$, $45 \mathrm{COOH}$ and $180 \mathrm{COOH}$, according to the oxidation times of 15, 45 and $180 \mathrm{~min}$, respectively (Table 1).

Tartaric acid-catalysed esterification

Tartaric acid-catalysed esterification was performed as described elsewhere (Zhao et al. 2010). The oxidized cellulosic textile (approximately $100 \mathrm{mg}$ ) was immersed in $10 \mathrm{~mL}$ of betulin solution in toluene with a concentration of $0.16 \mathrm{~mol} \mathrm{~L} \mathrm{~L}^{-1}, 25 \mathrm{mg}$ of tartaric acid $(0.16 \mathrm{mmol}, 10 \mathrm{~mol} \%)$ and activated molecular sieves. The reaction was carried out at $110{ }^{\circ} \mathrm{C}$ for designated times of 6,24 or $72 \mathrm{~h}$ for each type of oxidized textile to obtain 9 different betulingrafted textile samples, as shown in Table 1. After cooling to ambient temperature, the cellulosic textiles were extracted (Soxhlet) using THF first then with water, followed by air dry overnight prior to further use.

Fourier transform infrared (FTIR) analysis

FTIR spectra of all samples were recorded on a PerkinElmer Spectrum 2000 FTIR equipped with a heatcontrolled single-reflection attenuated total reflection (ATR) accessory (Golden Gate heat-controlled) under absorbance mode. Each spectrum was recorded between 4000 and $600 \mathrm{~cm}^{-1}$ with 16 scans and $4 \mathrm{~cm}^{-1}$ resolutions. All FTIR spectra were normalized to the band from 1320 to $1310 \mathrm{~cm}^{-1}$.

\section{Carboxyl content determination}

Carboxyl content (CC) in the oxidized textile samples $(15 \mathrm{COOH}, 45 \mathrm{COOH}$ and $180 \mathrm{COOH})$ was determined by an acid-base titration procedure adapted from calcium-acetate methods described elsewhere (Kumar and Yang 2002; Marković et al. 2017; Praskalo et al. 2009; Yackel and Kenyon 1942). Oxidized textile sample $(500 \mathrm{mg}$ ) was dipped into a solution containing $50 \mathrm{~mL}$ of deionized water and $30 \mathrm{~mL}$ of $0.5 \mathrm{M}$ sodium acetate solution. After $2 \mathrm{~h}$ of ion interchange reaction under constant shaking, $30 \mathrm{~mL}$ of the liquid was transferred out and was titrated with $0.01 \mathrm{M}$ sodium hydroxide with phenolphthalein as an indicator. Each measurement was repeated in triplicate, and the carboxyl content ( $\mathrm{mmol} \mathrm{g}^{-1}$ ) was calculated using the following equation:

$\mathrm{COOH}=\frac{\frac{80}{30} \times 0.01 \mathrm{M} \times \mathrm{V}(\mathrm{NaOH})}{\mathrm{m} \times\left(1-\frac{\mathrm{w}}{100}\right)}$

where $0.01 \mathrm{M}$ is the concentration of $\mathrm{NaOH}$, $\mathrm{V}(\mathrm{NaOH})$ is the volume $(\mathrm{mL})$ of $\mathrm{NaOH}$ solution used for titration, and $\mathrm{m}$ and $\mathrm{w}$ are the weight $(\mathrm{g})$ and moisture content $(\%)$ of the oxidized textiles added for titration, respectively. 
Table 1 Experimental design for the preparation of each sample

\begin{tabular}{|c|c|c|c|}
\hline & Denotation & Duration of oxidation (min) & Duration of esterification (h) \\
\hline Original textile & Ref. cotton & - & - \\
\hline \multirow[t]{3}{*}{ Oxidized textile } & $15 \mathrm{COOH}$ & 15 & - \\
\hline & $45 \mathrm{COOH}$ & 45 & - \\
\hline & $180 \mathrm{COOH}$ & 180 & - \\
\hline \multirow[t]{9}{*}{ Betulin-grafted textile } & $15 \mathrm{COOB} 6$ & 15 & 6 \\
\hline & $15 \mathrm{COOB} 24$ & 15 & 24 \\
\hline & $15 \mathrm{COOB} 72$ & 15 & 72 \\
\hline & $45 \mathrm{COOB} 6$ & 45 & 6 \\
\hline & $45 \mathrm{COOB} 24$ & 45 & 24 \\
\hline & $45 \mathrm{COOB} 72$ & 45 & 72 \\
\hline & 180COOB6 & 180 & 6 \\
\hline & $180 \mathrm{COOB} 24$ & 180 & 24 \\
\hline & $180 \mathrm{COOB} 72$ & 180 & 72 \\
\hline
\end{tabular}

Degree of oxidation (DO)

The DO was calculated using the following equation:

$\mathrm{DO}=\frac{162 \times \mathrm{CC}}{1-14 \times \mathrm{CC}}$

where $\mathrm{CC}$ is the carboxyl content $\left(\mathrm{mol} \mathrm{g}^{-1}\right)$, $162 \mathrm{~g} \mathrm{~mol}^{-1}$ is the molecular weight of a $\beta$-Dglucopyranose unit in cellulose, and $14 \mathrm{~g} \mathrm{~mol}^{-1}$ is the difference between the molecular weight of a $\mathrm{COOH}$ group and that of a $\mathrm{CH}_{2} \mathrm{OH}$ group.

Betulin fraction

Betulin fraction $(\mathrm{mg} / \mathrm{g})$ stands for the mass of covalently attached betulin per gram of betulin-grafted textile. Betulin-grafted textile was first weighed and then saponified (using $0.5 \mathrm{M} \mathrm{NaOH}$ for alkaline hydrolysis at $60{ }^{\circ} \mathrm{C}$ for $48 \mathrm{~h}$ ) to give betulin and textile containing sodium carboxylate groups. The textile was taken out accompanying by rinsing with water. The remaining insoluble betulin was then filtered followed by air drying and weighing. Finally, betulin fraction of each betulin-grafted textile was calculated: Betulin fraction $=\mathrm{m}_{\mathrm{b}} / \mathrm{m}_{\mathrm{t}}$, where $\mathrm{m}_{\mathrm{b}}$ is weight $(\mathrm{mg})$ of filtered betulin and $\mathrm{m}_{\mathrm{t}}$ is weight $(\mathrm{g})$ of betulin-grafted textile prior to saponification.
Tensile test

Tensile properties of betulin-grafted cellulosic textiles in the warp direction were determined using an Instron universal testing machine 5944 (UK) equipped with a $500 \mathrm{~N}$ load cell. All samples were conditioned at $23{ }^{\circ} \mathrm{C}$ and $50 \% \mathrm{RH}$ for $24 \mathrm{~h}$ prior to tests. The breaking tensile strength and elongation at break of at least three specimens $(5 \mathrm{~mm} \times 30 \mathrm{~mm})$ from each sample were tested at $23{ }^{\circ} \mathrm{C}$, with an initial distance between the grips of $10 \mathrm{~mm}$ and a separation rate of $1 \% \mathrm{~s}^{-1}$. The test results are presented as the mean \pm standard deviation.

Hydrophobicity test

The static water contact angle (WCA) was measured on a KSV Instrument CAM 200-m connected to a Basler A602f camera. A $4 \mu \mathrm{L}$ sessile water droplet was placed on 5 different positions of the surface, and pictures were taken every $4.8 \mathrm{~s}$ for a total period of $120 \mathrm{~s}$. The average contact angle and corresponding standard deviation for each sample were calculated over the 5 positions.

Antibacterial assays

The antibacterial tests were slightly modified from a standard method for antibacterial textiles (ISO 20743). The Gram-negative bacteria Escherichia coli (E. coli) 
K-12 and Gram-positive Staphylococcus aureus (S. aureus) (BioRad, Solna, Sweden) were incubated in a nutrient broth (Difco, Stockholm, Sweden) with continuous shaking at $37{ }^{\circ} \mathrm{C}$ for $18 \mathrm{~h}$, and the cells were harvested by centrifugation at $5000 \mathrm{rpm}$ for 5 min with a bench-top centrifuge (VWR, Stockholm, Sweden). The nutrient broth was exchanged with $1 / 4$ Ringer's solution, and the cells were washed twice before final redispersion. The antibacterial effects of the betulin-grafted textile were examined from the aspect of both bacterial removal and bacterial growth inhibition. In the bacterial removal test, $8 \mathrm{mg}$ each of the Ref. cotton and modified textiles (15COOB24, 45COOB72 and 180COOB24 betulin-grafted textile cut approximately $5 \mathrm{~mm} \times 15 \mathrm{~mm}$ ) were added, as well as the "+" control to Eppendorf mini tubes (maximum $2 \mathrm{~mL}$ ) along with a bacterial concentration of $2 \times 10^{6} \mathrm{CFU} \mathrm{mL}{ }^{-1}$. The samples were then placed in an incubator with continuous shaking at $37{ }^{\circ} \mathrm{C}$ for $18 \mathrm{~h}$. After incubation, $0.2 \mathrm{~mL}$ of solution from each sample was taken and diluted in $1.8 \mathrm{~mL}$ of $1 / 4$ Ringer' $\mathrm{s}$ solution. The solutions were further diluted 3- and 4-fold, and $1 \mathrm{~mL}$ of each diluted solution was dropped onto a piece of PetrifilmTM (3 M, Sollentuna, Sweden). The bacterial colony counts were carried out by a particle analyser using ImageJ.

To test the bacterial growth inhibition, $0.2 \mathrm{~mL}$ of nutrient broth was added to each textile-bacteria suspension after the bacterial removal test. All samples were incubated for $18 \mathrm{~h}$ at $37{ }^{\circ} \mathrm{C}$ with continuous shaking. The optical density (OD) of each suspension was determined at $\lambda=620 \mathrm{~nm}$ on a MultiSkan FC microplate spectrophotometer (Thermo Scientific, Stockholm, Sweden) to estimate the number of bacteria. The true viability was also examined by counting the number of bacterial colonies on the Petrifilm.

\section{Scanning electron microscopy (SEM)}

SEM images were captured by a Hitachi S-4800 fieldemission scanning electron microscope (JEOL Ltd., Tokyo, Japan). Textile samples of Ref. cotton, $180 \mathrm{COOH}$ and $180 \mathrm{COOB} 72$ were adhered onto a round metal stud and were coated with a $5 \mathrm{~nm}$ platinum layer by a Cressington 208HR high-resolution sputter coater (Cressington, England, UK) that was connected to a Cressington thickness monitor controller. The textile samples incubated with bacteria were immersed in $2.5 \%$ glutaraldehyde in $0.1 \mathrm{M}$ phosphate buffer ( $\mathrm{pH} 7.4)$ overnight at $4{ }^{\circ} \mathrm{C}$ for proper fixation. Thereafter, the specimens were rinsed in water and then solvent exchanged in 50\%, 70\%, 90\%, 96\% and absolute ethanol for $10 \mathrm{~min}$, respectively, and finally dried using a critical point dryer. The dried specimens were coated with a $10 \mathrm{~nm}$ platinum layer and analysed under the SEM at a voltage of $5 \mathrm{kV}$.

\section{Results and discussion}

Oxidation of cellulose

The FTIR spectra of Ref. cotton, $15 \mathrm{COOH}, 45 \mathrm{COOH}$ and $180 \mathrm{COOH}$ are shown in Fig. 1a. The noteworthy absorption band at $1727 \mathrm{~cm}^{-1}$ corresponds to the $\mathrm{C}=\mathrm{O}$ stretching vibration of carboxyl groups (Habibi et al. 2006) and was clearly identified in each oxidized sample, except in Ref. cotton. This indicates that the primary hydroxyl groups at the $\mathrm{C} 6$ positions in cellulose were oxidized to carboxyl groups. The carboxyl content (CC) and degree of oxidation (DO) of $15 \mathrm{COOH}, 45 \mathrm{COOH}$ and $180 \mathrm{COOH}$ were determined (Table 2). Both the CC and DO of cellulose slightly increased when the reaction was prolonged from 15 to $45 \mathrm{~min}$. When the oxidation reaction continued to $180 \mathrm{~min}$, the CC and DO increased to a maximum value of approximately $500 \mu \mathrm{mol} \mathrm{g}-1$ and $8.5 \%$, respectively. Results from the FTIR analyses and carboxyl content determinations successfully verified the desired oxidation.

\section{Esterification process}

Prior to ion exchange treatment, sample $180 \mathrm{COOH}$ was designated as $180 \mathrm{COONa}$, which was also analysed by FTIR, along with sample $180 \mathrm{COOH}$ and Ref. cotton (Fig. 1b). The band at $1604 \mathrm{~cm}^{-1}$ due to $\mathrm{C}=\mathrm{O}$ stretching vibration confirmed the existence of carboxylate groups (Fujisawa et al. 2011), and this band overlapped with the band at $1640 \mathrm{~cm}^{-1}$ arising from a small amount of adsorbed water (da Silva Perez et al. 2003). After the ion exchange treatment, the carboxylate groups were converted to carboxyl groups, and thus the $\mathrm{C}=\mathrm{O}$ absorption band at $1604 \mathrm{~cm}^{-1}$ was shifted to $1727 \mathrm{~cm}^{-1}$. This fact is useful for identifying the ester bonds that exist among abundant carboxyl groups. Since the $\mathrm{C}=\mathrm{O}$ absorption 


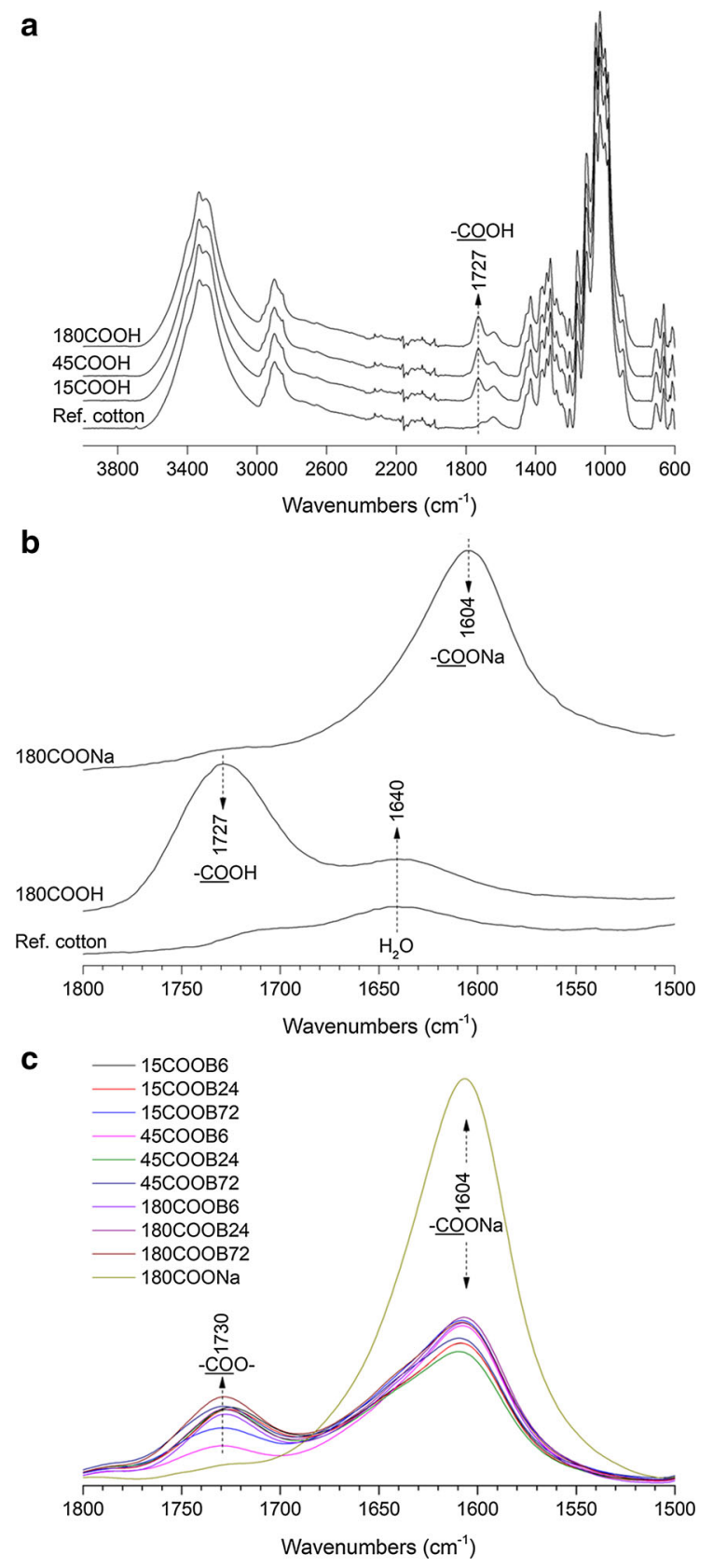

Fig. 1 FTIR absorbance spectra of a Ref. cotton and its oxidized products after $15 \mathrm{~min}(15 \mathrm{COOH}), 45 \mathrm{~min}(45 \mathrm{COOH})$, and $180 \mathrm{~min}(180 \mathrm{COOH})$; b Ref. cotton and its 180-min oxidized products before (180COONa) and after $(180 \mathrm{COOH})$ ion exchange through an acidic treatment; $\mathbf{c}$ all betulin-grafted textile samples after alkali treatment ion exchange, as well as 180COONa

band of ester bonds majorly overlaps with that of carboxyl groups at approximately $1730 \mathrm{~cm}^{-1}$, those carboxyl groups should be converted to carboxylate groups by alkali treatment in order to differentiate the carboxyl bands from the ester bands. The alkali treatment should be carried out with an alkaline solution at low concentration for a short period of time at room temperature to cause ion exchange, but with little hydrolysis. Herein, all 9 betulin-grafted samples (Table 1) were immersed in $\mathrm{NaOH}$ solution at $\mathrm{pH} 10$ for $1 \mathrm{~h}$ at room temperature, followed by washing thoroughly with water to convert the unconsumed $\mathrm{COOH}$ groups to $-\mathrm{COONa}$, as described elsewhere $(\mathrm{Li}$ et al. 2017). The alkali-treated samples were also analysed by FTIR, along with $-180 \mathrm{COONa}$ (Fig. 1c). As seen, after shifting the $-\mathrm{COOH}$ band at $1727 \mathrm{~cm}^{-1}$ to a $-\mathrm{COONa}$ band at $1604 \mathrm{~cm}^{-1}$ by alkali treatment, the band assigned to the ester bonds at $1730 \mathrm{~cm}^{-1}$ is clearly exposed in all betulin-grafted samples, suggesting that the esterification was successful. However, the peak heights of the bands at $1730 \mathrm{~cm}^{-1}$ (Fig. 1c) associated with ester bonds is different among those samples. A stronger $1730 \mathrm{~cm}^{-1}$ peak indicates a greater number of ester bonds present. Moreover, it is worth noting that the so-called betulin used in esterification is actually the extractive directly obtained from birch bark, and it contains $80 \%$ betulin as determined. This purity corresponds well to the average betulin content of birch bark extractive, according reported literatures (Krasutsky 2006). Along with betulin as the major component, other impurities consist the rest $20 \%$ of the extractive, such as betulinic acid (4.3\%), betulinic aldehyde (1.2\%) and lupeol (7.9\%) (Fǎlămaş et al. 2011; O'Connell et al. 1988). It should be emphasized that those impurities are 4-5 times less reactive than betulin in the esterification since they only own secondary hydroxyl groups (Scheme 1) (Jeromenok 2012). The combination of low content and low reactivity of the impurities will result in the dominated involvement of betulin in the esterification. The fraction of covalently attached betulin on each betulin-grafted textile is shown in Table 3.

\section{Surface morphology}

Changes in the morphology of textile samples from each step were observed by SEM. Ref. cotton (Fig. 2a) contains longitudinal smooth fibers and rough fibres distributed by tiny grooves at the micrometre level, which is a classic characteristic of pristine cellulosic textile fibre surfaces (Tissera et al. 2015; Xue et al. 
Table 2 Carboxyl content and degree of oxidation of oxidized textile samples

\begin{tabular}{lcll}
\hline Sample & Duration of oxidation $(\mathrm{min})$ & Carboxyl group content ${ }^{\mathrm{a}}\left(\mu \mathrm{mol} \mathrm{g}^{-1}\right)$ & Degree of oxidation $(\%)$ \\
\hline $15 \mathrm{COOH}$ & 15 & $343 \pm 2$ & 5.6 \\
$45 \mathrm{COOH}$ & 45 & $361 \pm 12$ & 5.9 \\
$180 \mathrm{COOH}$ & 180 & $522 \pm 13$ & 8.5 \\
\hline
\end{tabular}

${ }^{\mathrm{a}}$ Data are presented as the mean \pm standard deviation of three replicates

Table 3 Betulin fraction of betulin-grafted textiles ${ }^{\mathrm{a}}$

\begin{tabular}{ll}
\hline Sample & Fraction (mg/g sample) \\
\hline 15 COOB6 & N/A \\
15 COOB24 & $46 \pm 16$ \\
15 COOB72 & $91 \pm 21$ \\
45 COOB6 & N/A \\
45 COOB24 & $70 \pm 10$ \\
45 COOB72 & $106 \pm 24$ \\
180 COOB6 & $48 \pm 17$ \\
180 COOB24 & $95 \pm 14$ \\
180 COOB72 & $141 \pm 25$
\end{tabular}

Data are presented as the mean \pm standard deviation of three replicates; N/A: data are not available

${ }^{\mathrm{a}}$ Betulin fraction stands for weight $(\mathrm{mg})$ of grafted betulin on per gram of betulin-grafted textile

2016). The grooves will lead to surface roughness (Xue et al. 2016) in favour of hydrophobization treatment. Generally, the oxidation was mild, since compared with Ref. cotton (Fig. 2a), no obvious damage was seen on the fibre surface of the oxidized one (Fig. 2b). On the other hand, sample 180COOB72 (Fig. 2c), obtained after a long esterification process, showed some burls or nubs, with dimensions ranging from 0.5 to $1 \mathrm{~nm}$, as seen in the zoomed-in area of Fig. 2c. The burls or nubs were unidentified and require further investigation.

An additional control sample was prepared by dipping a piece of Ref. cotton into a betulin solution that was prepared identically to that prior to the esterification process $\left(0.16 \mathrm{~mol} \mathrm{~L}^{-1}\right.$, toluene $)$ for $5 \mathrm{~min}$, followed by air drying. This control sample was also analysed by SEM to investigate the original morphology of free betulin particles (Fig. 2d). The fibre surface was densely covered by cylinder-like betulin particles, with an average length of approximately $5 \mu \mathrm{m}$. This special cylinder shape of free betulin particles corresponds well to the findings in our previous study (Huang et al. 2018). Compared with the textile fibres in Fig. 2d that were densely covered by free betulin particles, it can be concluded that in sample 180COOB72, the non-attached betulins were removed to a large extent by Soxhlet extraction, since no remaining betulin particles could be seen.

\section{Wettability}

The wettability of each sample after esterification was determined by water contact angle measurements. Only samples 45COOB72, 180COOB24, $180 \mathrm{COOB} 72$ and $15 \mathrm{COOB} 72$ exhibited measurable water contact angles. Figure 3 shows the water contact angles of the above four samples as a function of time as well as the slide views of the water droplets captured during the test. The water contact angle of $15 \mathrm{COOB} 72$ reduced from $128^{\circ}$ to $77^{\circ}$, with a steady trend over $2 \mathrm{~min}$. Particularly, the value was lower than $90^{\circ}$ after $100 \mathrm{~s}$, indicating that the sample was hydrophilic after that time point. In the case of the five easily wetted samples, perhaps due to an insufficient reaction time of either oxidation or esterification, the amount of covalently attached betulin might be too low to contribute to improving the hydrophobicity of the samples. This could result in the capillary force of textile fibres being large enough to wick water droplets into the samples despite the small amount of hydrophobicity provided by trace levels of grafted betulin (Bae et al. 2009).

By contrast, the static water contact angles of 45COOB72, 180COOB24 and 180COOB72 were generally constant over time (Fig. 3) with similar mean values, suggesting that stable hydrophobicity was achieved. Constructively, higher degree of esterification with betulin leads to higher hydrophobicity on the product surface. 

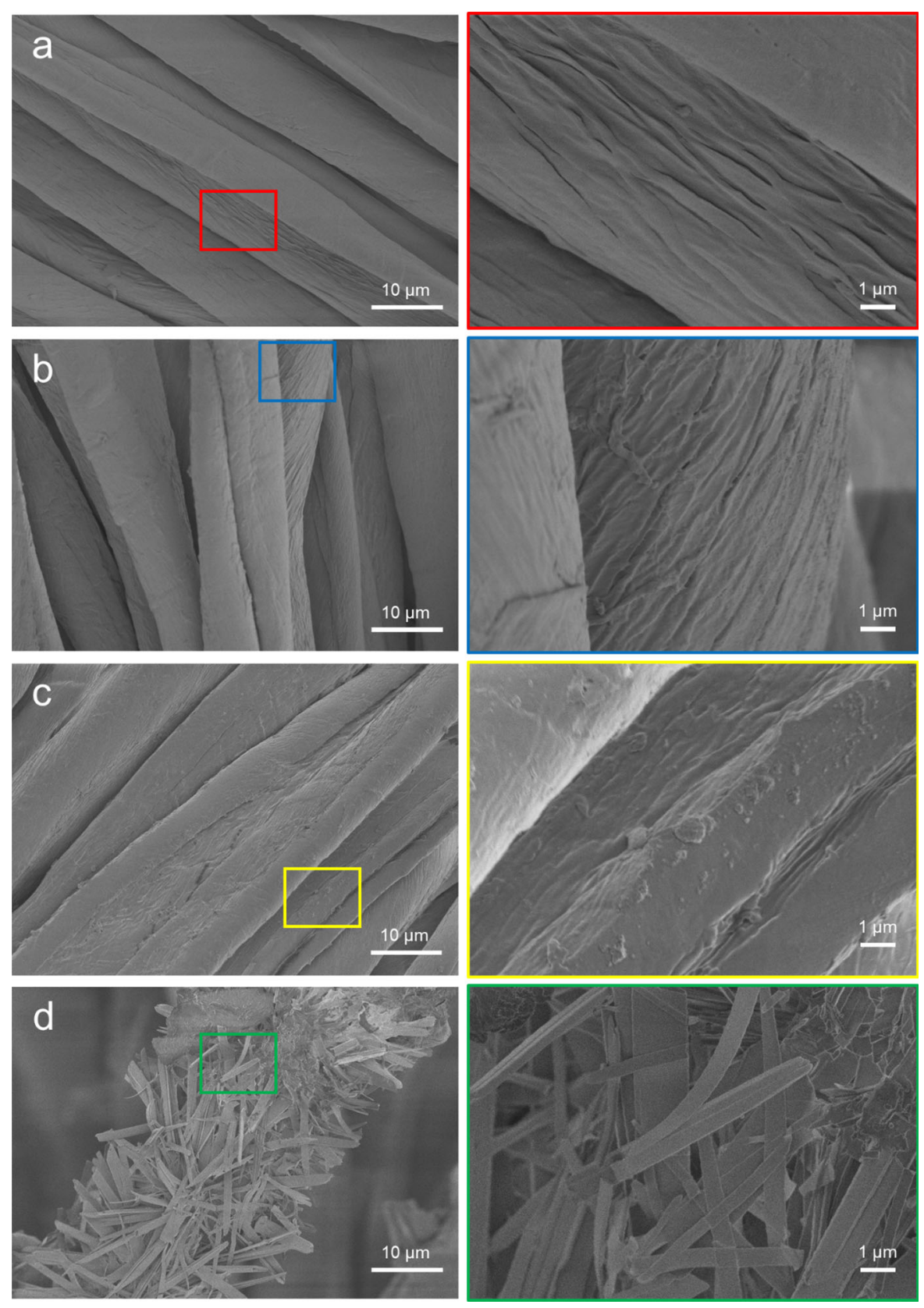

Fig. 2 SEM images of a Ref. cotton: untreated cellulosic textile, b 180COOH: cellulosic textile treated with $180 \mathrm{~min}$ of oxidation, c 180COOB72: cellulosic textile treated with

$180 \mathrm{~min}$ of oxidation, followed by $72 \mathrm{~h}$ of esterification, and d Ref. cotton impregnated with $0.16 \mathrm{~mol} \mathrm{~L}^{-1}$ betulin solution in toluene

Betulin shows desirable hydrophobicity, as its $\mathrm{CH}$ groups make it a low surface energy chemical, as discussed in our previous study (Huang et al. 2018). Since the samples were sufficiently Soxhlet extracted, the non-attached betulin molecules were removed, which was also confirmed by SEM. Therefore, the

exhibited hydrophobicity of samples 45COOB72, $180 \mathrm{COOB} 24$ and $180 \mathrm{COOB} 72$ can mainly be attributed to the covalently attached betulin moieties on the sample surface. Additionally, the roughness caused by hairy protruding textile fibres on a macro scale, and dense grooves on textile fibre surfaces on a micro 


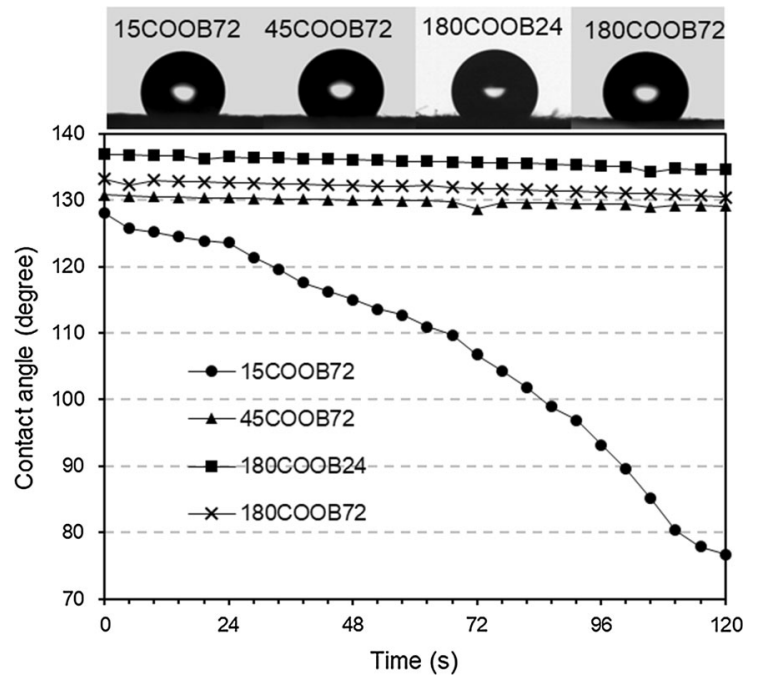

Fig. 3 Water contact angle of 45COOB72, 180COOB24, $180 \mathrm{COOB} 72$ and $15 \mathrm{COOB} 72$ as a function of time. XCOOBY stands for a sample prepared by $\mathrm{X}$ min of oxidation, followed by $\mathrm{Y} h$ of esterification

scale, can also contribute to hydrophobicity, since the combination of surface roughness and surface free energy affects the wettability of a surface (Cassie and Baxter 1944).

\section{Antibacterial property}

The antibacterial effect was evaluated by examining the number of viable bacteria after $18 \mathrm{~h}$ when inoculated with the tested textile sample, with and without added nutrients. The reduction of bacteria in nutrient-poor conditions is shown in Fig. $4 \mathrm{a}$ as the number of bacteria remaining after incubation and the percentage of bacterial removal compared to the positive reference. In Fig. 4a it can be seen that Ref. cotton, on which no betulin was grafted, showed no bacterial reduction, rather, it had an enhanced bacterial proliferation of 3.9 times for E. coli and 2.4 times for $S$. aureus. This indicated that in low-nutrient conditions, the polysaccharide-based textile was itself used as a nutrient source for both the Gram-negative and Gram-positive bacteria. A similar phenomena was also observed for cellulosic pulp fibres (Chen et al. 2017). Conversely, sample 180COOB24 showed an obvious reduction of both Gram-negative E. coli and Gram-positive $S$. aureus. It was particularly effective against $E$. coli, with a reduction of up to $99.94 \%$. The other two samples, 45COOB72 and 15COOB24, also
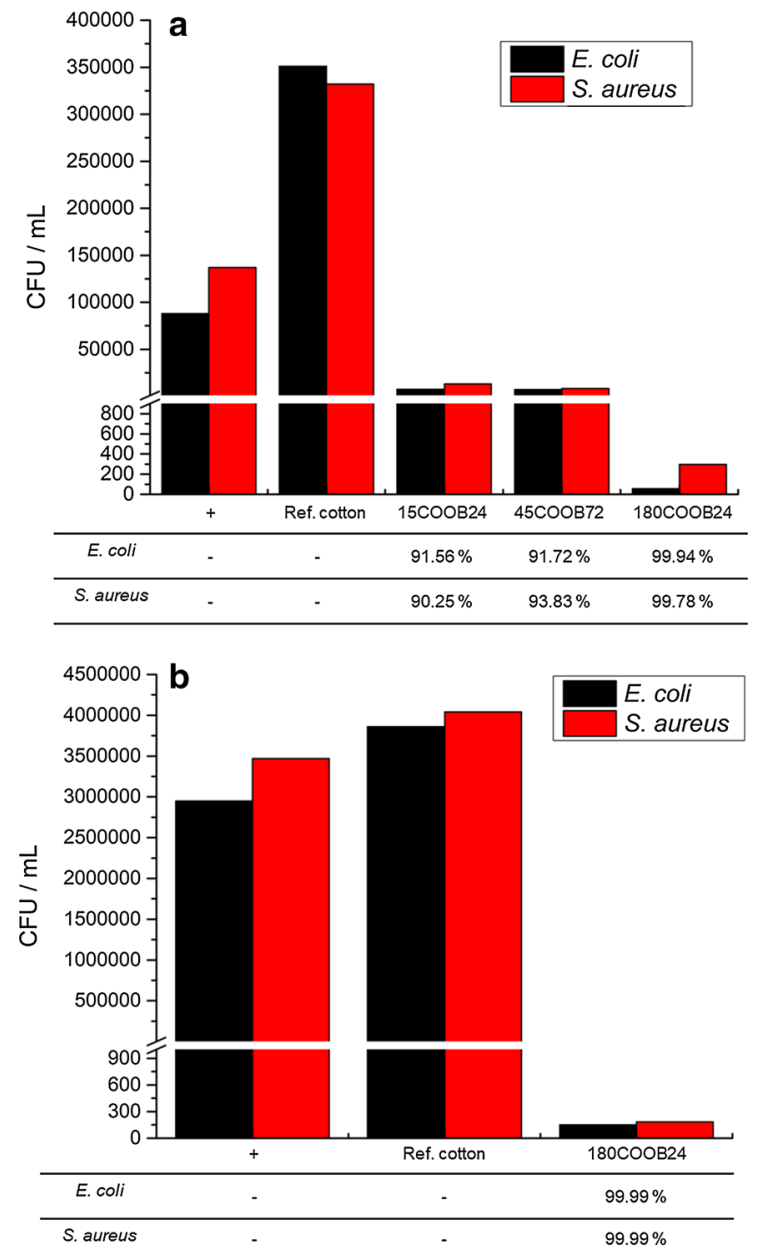

Fig. 4 Antibacterial properties: a bacterial concentration after $18 \mathrm{~h}$ of incubation with textile samples in bacterial reduction tests. The reduction percentage is shown in the tables below; b bacterial concentration and inhibition percentage in the bacterial growth inhibition tests

showed greater than $90 \%$ bacterial reduction; however, they were much less efficient than 180COOB24, which had the highest hydrophobicity. Samples 15COOB24 and 45COOB72 did not show obvious bacterial growth inhibition capabilities. Only one of the betulin-grafted samples, 180COOB24, had a significant bacterial growth inhibitory effect (presented in Fig. 4b), with a bacterial reduction of up to $99.99 \%$ for both E. coli and S. aureus. Compared Fig. 4a with Fig. 4b, the Ref. cotton showed higher bacterial growth enhancement than in the bacterial reduction test due to the accessible nutrients that were in the bacterial solution. 
Table 4 Bacterial reduction of some textile after antibacterial treatment with the reagents indicated

\begin{tabular}{lllll}
\hline Substrate & Antibacterial reagent & Bacterial type & Bacterial reduction & Reference \\
\hline Cotton fabric & Silver Nanoparticles & E. coli/S. aureus & $99.26 \% / 99.01 \%$ & Zhang et al. (2009) \\
Cotton fabric & Silver Nanoparticles & E. coli/S. aureus & $95 \% / 96.4 \%$ & Hebeish et al. (2011) \\
Bamboo rayon fabric & $\mathrm{CuO}$ nanoparticle & E. coli/S. aureus & $99.47 \% / 100 \%$ & Teli and Sheikh $(2014)$ \\
Cotton fabric & ZnO nanoparticles & E. coli/S. aureus & $99.88 \% / 99.98 \%$ & Singh et al. (2012) \\
Cotton fabric & Nanosized silver colloidal solution & K. pneumonia/S. aureus & $99.9 \% / 99.9 \%$ & Lee et al. (2003) \\
\hline
\end{tabular}

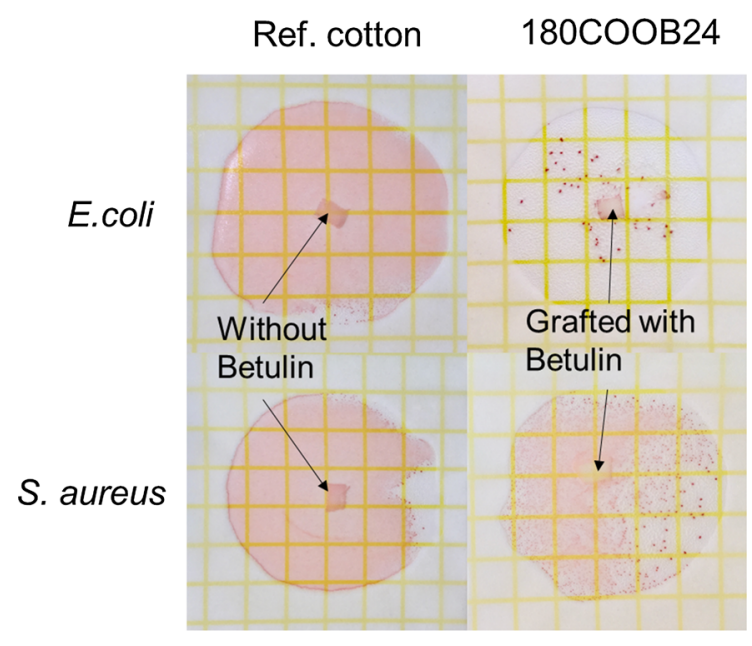

Fig. 5 Ref. cotton and 180COOB24 incubated on Petrifilms after an $18 \mathrm{~h}$ immersion in $E$. coli or $S$. aureus solution
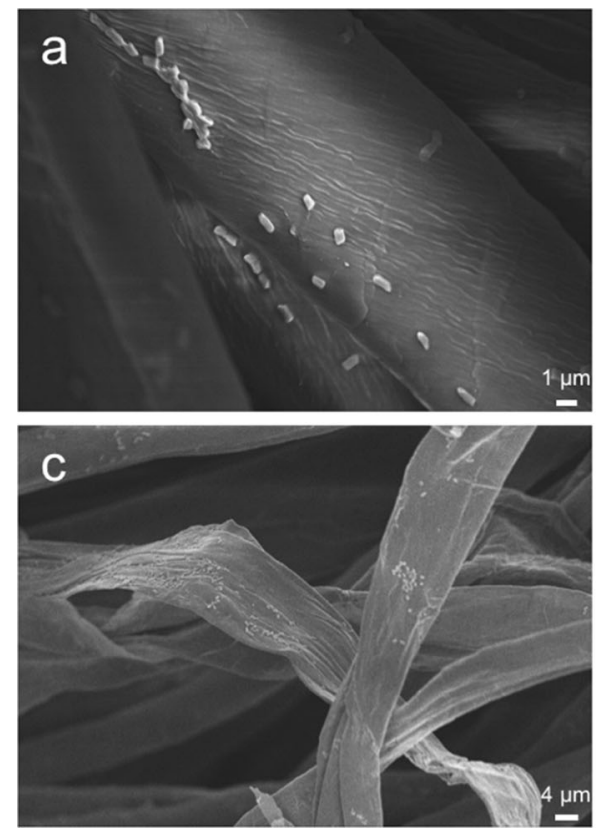

These results from antibacterial assays are comparable to those reported (Table 4): the bacterial reduction (BR) of cotton fabric modified with silver nanoparticles were in the range of $95-99.26 \%$ (Hebeish et al. 2011; Zhang et al. 2009), while the BR is high as $99.9 \%$ by modification with nanosized silver colloidal solution (Lee et al. 2003). ZnO nanoparticles can also be used for rendering cotton fabric with antibacterial property, and the BR can exceed $99 \%$ as well (Singh et al. 2012). Additionally, by using $\mathrm{CuO}$ nanoparticle, the modified bamboo rayon fabric could even reach a BR of $100 \%$ against $S$. aureus, as reported (Teli and Sheikh 2014).

Few systematic studies of antibacterial properties of betulin have been reported, especially regarding betulin-functionalized materials. Based on our investigation, the textiles modified by betulin with more
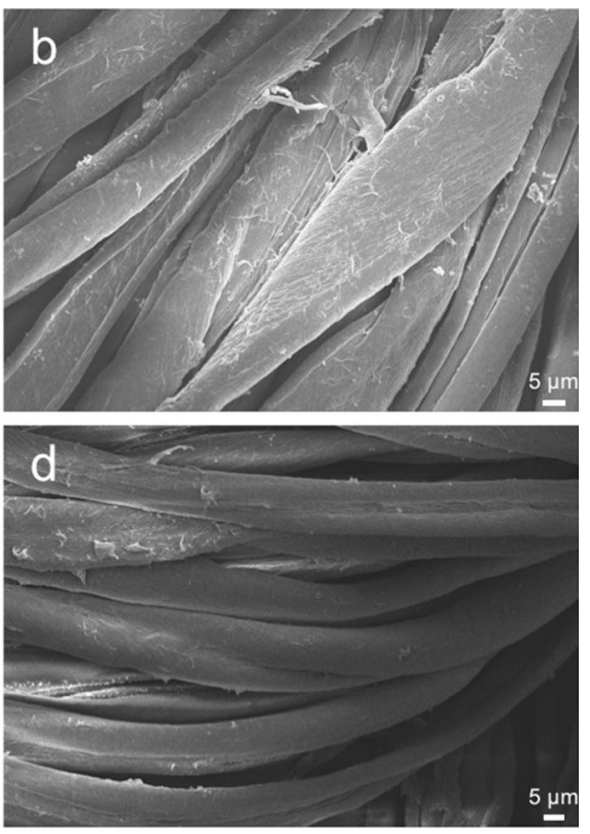

Fig. 6 SEM images of E. coli growth on a Ref. cotton, b 180COOB24; S. aureus growth on c Ref. cotton, d $180 C O O B 24$ 


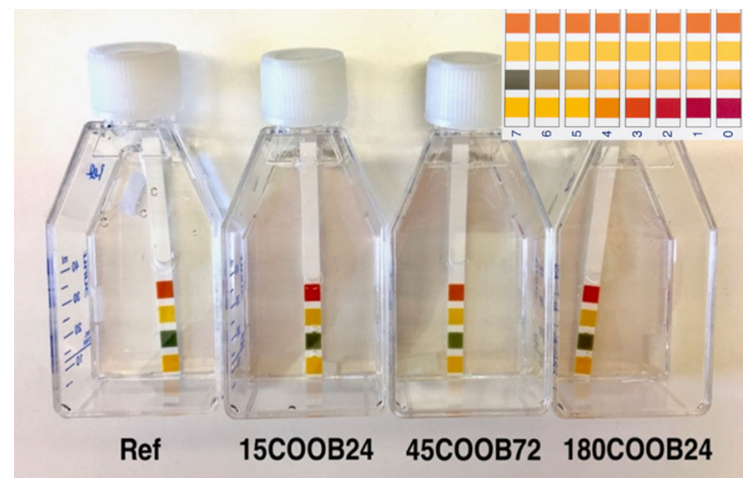

Fig. 7 The $\mathrm{pH}$ of 4 different samples incubated in $1 / 4$ Ringer's solution after $18 \mathrm{~h}$ at $37{ }^{\circ} \mathrm{C}$

carboxylic acid groups, followed by $24 \mathrm{~h}$ of esterification, showed good antibacterial effects against both Gram-positive $S$. aureus and Gram-negative E. coli, including bacterial reduction in poor nutrient conditions and bacterial growth inhibition in the presence of nutrients. In Fig. 5, the small square of textiles are located in the middle of each Petrifilm, and it can be observed that the Ref. cotton were covered by bacteria (red colour), whereas the sample textile 180COOB24 was not "invaded" (original white colour). The textile samples were further examined under SEM, as shown in Fig. 6. It can be observed that many more bacteria grew on the Ref. cotton than on the 180COOB24 sample.

A strong antibacterial effect against both Grampositive $S$. aureus and Gram-negative $E$. coli was seen in both the quantitative results of the bacterial solutions and in the qualitative microscopic images. The results indicate that the irreversibly grafted betulin textiles can have not only a large impact on the bacterial activities in the surrounding solutions but can also deactivate bacterial proliferation on the surface. To verify this, the $\mathrm{pH}$ was examined for all samples that were incubated in Ringer's solution at $37{ }^{\circ} \mathrm{C}$ after $18 \mathrm{~h}$, since the $\mathrm{pH}$ of the aqueous environment could interfere with the bacterial viability, i.e., lower viability at lower $\mathrm{pH}$ (Conner and Kotrola 1995; Leyer et al. 1995). However, in the current study, no $\mathrm{pH}$ change was observed, as shown in Fig. 7, which indicates that the $\mathrm{pH}$ was consistently 7 . It has been reported that betulin is able to suppress the inflammation caused by E. coli and $S$. aureus (Guo et al. 2015; Wu et al. 2014). Combined with our studies, the decreased expression of inflammatory proteins could be due to the decreased bacterial viability caused by contact with betulin. It has also been reported that a series of triterpenoid chemical compounds were found to have antibacterial activity against E. coli and S. aureus (Dzubak et al. 2006). However, the specific antibacterial mechanisms remain unclear, and an important role for betulin use in possible medical applications could be discovered in future studies.

\section{Mechanical properties}

Mechanical properties of the textiles, such as tensile strength, dramatically decreased as a result of oxidation (Table 5). It has been reported that the degree of polymerization (DP) of cellulose oxidized in a TEMPO/NaClO/ $/ \mathrm{NaClO}_{2}$ system decreases with an extension of the oxidation time due to the cleavage of glycoside bonds (Shibata and Isogai 2003). A reduced DP will result in an inevitable reduction of mechanical properties (Saito et al. 2009). The tensile strength of
Table 5 Tensile properties including breaking tensile strength and elongation at break of Ref. cotton, oxidized textiles and betulin-grafted textiles

\begin{tabular}{lcc}
\hline Sample & Tensile strength $(\mathrm{MPa})$ & Elongation at break $(\%)$ \\
\hline Ref. cotton & $30.5 \pm 2.0$ & $21.6 \pm 8.0$ \\
$15 \mathrm{COOH}$ & $19.9 \pm 1.8$ & $14.0 \pm 0.5$ \\
$45 \mathrm{COOH}$ & $7.8 \pm 0.6$ & $24.8 \pm 0.6$ \\
$180 \mathrm{COOH}$ & $6.6 \pm 0.3$ & $22.2 \pm 0.5$ \\
$15 \mathrm{COOB} 24$ & $5.7 \pm 0.5$ & $22.6 \pm 1.3$ \\
$15 \mathrm{COOB} 72$ & $4.5 \pm 0.7$ & $21.6 \pm 0.7$ \\
$45 \mathrm{COOB} 24$ & $5.7 \pm 0.7$ & $10.1 \pm 0.4$ \\
$45 \mathrm{COOB} 72$ & $2.9 \pm 0.5$ & $8.3 \pm 0.6$ \\
$180 \mathrm{COOB} 24$ & $4.2 \pm 0.8$ & $19.3 \pm 0.9$ \\
$180 \mathrm{COOB} 72$ & $2.2 \pm 0.2$ & $17.9 \pm 0.6$
\end{tabular}


betulin-grafted textiles also decreased upon increased esterification times (Table 5) due to either depolymerization of cellulose at high temperatures or the hydrolysis of cellulose caused by tartaric acid.

\section{Conclusions}

Hydrophobic and antibacterial cellulosic textile fibres were successfully prepared by grafting betulin onto carboxyl-functionalized cellulose via esterification. Different oxidation and esterification time durations were performed. The material prepared through $180 \mathrm{~min}$ of oxidation followed by $24 \mathrm{~h}$ of esterification exhibited the highest static water contact angle of $136^{\circ}$ and exceeded a bacterial reduction of $99 \%$. This new created functional textile would be a potential alternative for fabricating sportswear or medical mattress and bandages where waterproof or antibacterial properties are needed. However, at the current stage, this study just aims to provide an idea for the simple fabrication of functional materials and more importantly, the exhibited method can be envisaged to be applied to other cellulose sources (e.g., microfibrillated cellulose) to achieve the goal of functionalization. It is also true, however, that further research involving both optimization of the fastness of such properties and establishment of new cellulose-betulin system should be considered if the product is expected to bear a commercial viable application potential.

Acknowledgments The China Scholarship Council is thanked for financially supporting Tianxiao Huang and Chao Chen's study.

Open Access This article is distributed under the terms of the Creative Commons Attribution 4.0 International License (http:// creativecommons.org/licenses/by/4.0/), which permits unrestricted use, distribution, and reproduction in any medium, provided you give appropriate credit to the original author(s) and the source, provide a link to the Creative Commons license, and indicate if changes were made.

\section{References}

Bae GY, Min BG, Jeong YG, Lee SC, Jang JH, Koo GH (2009) Superhydrophobicity of cotton fabrics treated with silica nanoparticles and water-repellent agent. J Colloid Interface Sci 337:170-175
Berbel J, Posadillo A (2018) Review and analysis of alternatives for the valorisation of agro-industrial olive oil by-products. Sustainability 10:237

Cao D, Zhao G, Yan W (2007) Solubilities of betulin in fourteen organic solvents at different temperatures. J Chem Eng Data 52:1366-1368

Cassie A, Baxter S (1944) Wettability of porous surfaces. Trans Faraday Soc 40:546-551

Chen C, Illergård J, Wågberg L, Ek M (2017) Effect of cationic polyelectrolytes in contact-active antibacterial layer-bylayer functionalization. Holzforschung 71:649-658

Conner DE, Kotrola JS (1995) Growth and survival of Escherichia coli $\mathrm{O} 157: \mathrm{H} 7$ under acidic conditions. Appl Environ Microbiol 61:382-385

da Silva Perez D, Montanari S, Vignon MR (2003) TEMPOmediated oxidation of cellulose III. Biomacromolecules 4:1417-1425

Dzubak P, Hajduch M, Vydra D, Hustova A, Kvasnica M, Biedermann D, Markova L, Urban M, Sarek J (2006) Pharmacological activities of natural triterpenoids and their therapeutic implications. Nat Prod Rep 23 (3):394

Fǎlămaş A, Pînzaru SC, Dehelean CA, Peev CI, Soica C (2011) Betulin and its natural resource as potential anticancer drug candidate seen by FT-Raman and FT-IR spectroscopy. J Raman Spectrosc 42:97-107. https://doi.org/10.1002/jrs. 2658

Fridén ME et al (2016) Evaluation and analysis of environmentally sustainable methodologies for extraction of betulin from birch bark with a focus on industrial feasibility. Green Chem 18:516-523. https://doi.org/10.1039/ c5gc00519a

Fujisawa S, Okita Y, Fukuzumi H, Saito T, Isogai A (2011) Preparation and characterization of TEMPO-oxidized cellulose nanofibril films with free carboxyl groups. Carbohydr Polym 84:579-583. https://doi.org/10.1016/j.carbpol. 2010.12.029

Grazhdannikov AE et al (2018) Selecting a green strategy on extraction of birch bark and isolation of pure betulin using monoterpenes. ACS Sustain Chem Eng 6:6281-6288. https://doi.org/10.1021/acssuschemeng.8b00086

Guo MY, Li WY, Zhang Z, Qiu C, Li C, Deng G (2015) Betulin suppresses $S$. aureus-induced mammary gland inflammatory injury by regulating PPAR-gamma in mice. Int Immunopharmacol 29:824-831. https://doi.org/10.1016/j. intimp.2015.08.035

Habibi Y, Chanzy H, Vignon MR (2006) TEMPO-mediated surface oxidation of cellulose whiskers. Cellulose 13:679-687. https://doi.org/10.1007/s10570-006-9075-y

Hafrén J, Córdova A (2005) Direct organocatalytic polymerization from cellulose fibers. Macromol Rapid Commun 26:82-86. https://doi.org/10.1002/marc.200400470

Hafrén J, Zou W, Córdova A (2006) Heterogeneous 'Organoclick' derivatization of polysaccharides. Macromol Rapid Commun 27:1362-1366. https://doi.org/10.1002/marc. 200600328

Hebeish A, El-Naggar M, Fouda MM, Ramadan M, Al-Deyab SS, El-Rafie M (2011) Highly effective antibacterial textiles containing green synthesized silver nanoparticles. Carbohydr Polym 86:936-940

Huang T, Li D, Ek M (2018) Water repellency improvement of cellulosic textile fibers by betulin and a betulin-based 
copolymer. Cellulose 25:2115-2128. https://doi.org/10. 1007/s10570-018-1695-5

Jeromenok J (2012) Polymers from the natural product betulin: a microstructural investigation. Universitätsbibliothek der Universität Potsdam, Potsdam

Krasutsky PA (2006) Birch bark research and development. Nat Prod Rep 23:919-942. https://doi.org/10.1039/b606816b

Kumar V, Yang T (2002) $\mathrm{HNO}_{3} / \mathrm{H}_{3} \mathrm{PO}_{4}-\mathrm{NANO}_{2}$ mediated oxidation of cellulose-preparation and characterization of bioabsorbable oxidized celluloses in high yields and with different levels of oxidation. Carbohydr Polym 48:403-412

Lee H, Yeo SY, Jeong SH (2003) Antibacterial effect of nanosized silver colloidal solution on textile fabrics. J Mater Sci 38:2199-2204

Leyer GJ, Wang L-L, Johnson EA (1995) Acid adaptation of Escherichia coli $\mathrm{O} 157: \mathrm{H} 7$ increases survival in acidic foods. Appl Environ Microbiol 61:3752-3755

Li D, Henschen J, Ek M (2017) Esterification and hydrolysis of cellulose using oxalic acid dihydrate in a solvent-free reaction suitable for preparation of surface-functionalised cellulose nanocrystals with high yield. Green Chem 19:5564-5567. https://doi.org/10.1039/c7gc02489d

Lu W, Sibley JL, Gilliam CH, Bannon JS, Zhang Y (2006) Estimation of US bark generation and implications for horticultural industries. J Environ Hortic 24:29-34

Marković D, Korica M, Kostić M, Radovanović Ž, Šaponjić Z, Mitrić M, Radetić M (2017) In situ synthesis of $\mathrm{Cu} / \mathrm{Cu}_{2} \mathrm{O}$ nanoparticles on the TEMPO oxidized cotton fabrics. Cellulose 25:829-841. https://doi.org/10.1007/s10570017-1566-5

Mishra SP, Manent A-S, Chabot B, Daneault C (2012) The use of sodium chlorite in post-oxidation of TEMPO-oxidized pulp: effect on pulp characteristics and nanocellulose yield. J Wood Chem Technol 32:137-148

O'Connell MM, Bentley MD, Campbell CS, Cole BJ (1988) Betulin and lupeol in bark from four white-barked birches. Phytochemistry 27:2175-2176

Praskalo J, Kostic M, Potthast A, Popov G, Pejic B, Skundric P (2009) Sorption properties of TEMPO-oxidized natural and man-made cellulose fibers. Carbohydr Polym 77:791-798. https://doi.org/10.1016/j.carbpol.2009.02. 028

Saito T, Hirota M, Tamura N, Kimura S, Fukuzumi H, Heux L, Isogai A (2009) Individualization of nano-sized plant cellulose fibrils by direct surface carboxylation using TEMPO catalyst under neutral conditions. Biomacromolecules 10:1992-1996
Sharoyan DE (2011) Pulping additives for a reduction of resin from Kraft pulp. U.S. Patent 8,052,840

Shibata I, Isogai A (2003) Depolymerization of cellouronic acid during TEMPO-mediated oxidation. Cellulose 10:151-158

Singh G, Joyce EM, Beddow J, Mason TJ (2012) Evaluation of antibacterial activity of $\mathrm{ZnO}$ nanoparticles coated sonochemically onto textile fabrics. J Microbiol Biotechnol Food Sci 2:106

Tanaka C, Yui Y, Isogai A (2016) TEMPO-mediated oxidation of cotton cellulose fabrics with sodium dichloroisocyanurate. J Fiber Sci Technol 72:172-178. https://doi.org/10. 2115/fiberst.2016-0027

Teli M, Sheikh J (2014) Bamboo rayon-copper nanoparticle composites as durable antibacterial textile materials. Compos Interfaces 21:161-171

Tissera ND, Wijesena RN, Perera JR, de Silva KMN, Amaratunge GAJ (2015) Hydrophobic cotton textile surfaces using an amphiphilic graphene oxide (GO) coating. Appl Surf Sci 324:455-463. https://doi.org/10.1016/j.apsusc. 2014.10.148

Wang Q, Fan X, Gao W, Chen J (2006) Characterization of bioscoured cotton fabrics using FT-IR ATR spectroscopy and microscopy techniques. Carbohydr Res 341:2170-2175

Wu Q, Li H, Qiu J, Feng H (2014) Betulin protects mice from bacterial pneumonia and acute lung injury. Microb Pathog 75:21-28. https://doi.org/10.1016/j.micpath.2014.08.005

Xue C-H, Zhang L, Wei P, Jia S-T (2016) Fabrication of superhydrophobic cotton textiles with flame retardancy. Cellulose 23:1471-1480. https://doi.org/10.1007/s10570016-0885-2

Yackel EC, Kenyon WO (1942) The oxidation of cellulose by nitrogen dioxide. J Am Chem Soc 64:121-127

Yu-hong Z, Tao Y, Yang W (2003) Extraction of betulin from bark of Betula platyphylla by supercritical carbon dioxide extraction. J For Res 14:202-204

Zhang F, Wu X, Chen Y, Lin H (2009) Application of silver nanoparticles to cotton fabric as an antibacterial textile finish. Fibers Polym 10:496-501

Zhao GL, Hafren J, Deiana L, Cordova A (2010) Heterogeneous "Organoclick" derivatization of polysaccharides: photochemical thiol-ene click modification of solid cellulose. Macromol Rapid Commun 31:740-744. https://doi.org/10. 1002/marc.200900764

Publisher's Note Springer Nature remains neutral with regard to jurisdictional claims in published maps and institutional affiliations. 